This document is the accepted manuscript version of the following article: Brüggemann, M., Hayeck, N., Bonnineau, C., Pesce, S., Alpert, P. A., Perrier, S., ... George, C. (2017). Interfacial photochemistry of biogenic surfactants: a major source of abiotic volatile organic compounds. Faraday Discussions, 200, 59-74. https://doi.org/10.1039/c7fd00022g

\title{
Interfacial photochemistry of biogenic surfactants: a major source of abiotic volatile organic compounds
}

Martin Brüggemann ${ }^{1, \Delta}$, Nathalie Hayeck ${ }^{1, \Delta}$, Chloé Bonnineau ${ }^{2}$, Stéphane Pesce ${ }^{2}$, Peter A. Alpert ${ }^{1, \dagger}$, Sébastien Perrier ${ }^{1}$, Christoph Zuth ${ }^{3}$, Thorsten Hoffmann ${ }^{3}$, Jianmin Chen ${ }^{4}$ and Christian George ${ }^{1, *}$

${ }^{1}$ Univ Lyon, Université Claude Bernard Lyon 1, CNRS, IRCELYON, F-69626, Villeurbanne, France

${ }^{2}$ Irstea, UR MALY, centre de Lyon-Villeurbanne, F-69616 Villeurbanne, France

${ }^{3}$ Institute of Inorganic and Analytical Chemistry, Johannes Gutenberg-Universität, 55128 Mainz, Germany

${ }^{4}$ Shanghai Key Laboratory of Atmospheric Particle Pollution and Prevention (LAP3), Fudan Tyndall

Centre, Shanghai 200433, China

${ }^{\Delta}$ These authors contributed equally.

tnow at: Paul Scherrer Institute, 5232 Villigen, Switzerland

*correspondence to: christian.george@ircelyon.univ-lyon1.fr

\section{Abstract}

Films of biogenic compounds exposed to the atmosphere are ubiquitously found on surfaces of cloud droplets, aerosol particles, buildings, plants, soils, and the ocean. These air/water interfaces host countless amphiphilic compounds concentrated there with respect to bulk water, leading to a unique chemical environment. Here, photochemical processes at the air/water interface of biofilm-containing solutions were studied, demonstrating abiotic VOC production from authentic biogenic surfactants under ambient conditions. Using a combination of online-APCI-HRMS and PTR-ToF-MS, unsaturated and functionalized VOCs were identified and quantified, giving emission fluxes comparable to previous field and laboratory observations. Interestingly, VOC fluxes increased with the decay of microbial cells in the samples, indicating that cell lysis due to cell death was the main source for surfactants, and VOC production. In particular, irradiation of samples containing solely biofilm cells without matrix components exhibited the strongest VOC production upon irradiation. In agreement with previous studies, LC-MS measurements of the liquid phase suggested the presence of fatty acids and known photosensitizers, possibly inducing the observed VOC production via peroxy-radical chemistry. Up to now such VOC emissions were directly accounted to high biological activity in surface waters. However, the obtained results suggest that abiotic photochemistry can lead to similar emissions into the atmosphere, especially in less biologically-active regions. Furthermore, chamber experiments suggested that oxidation $\left(\mathrm{O}_{3} / \mathrm{OH}\right.$-radicals) of the photochemically-produced VOCs leads to aerosol formation and growth, possibly affecting atmospheric chemistry and climate-related processes, such as cloud formation or the Earth's radiation budget. 
Air/water interfaces are omnipresent in the ambient atmosphere, reaching from the nm-scale for single aerosol particles to the surface of the ocean, which covers more than $70 \%$ of the Earth's surface. In the past, it was shown that unique photochemical reactions with significant implications for atmospheric processes can occur at such interfaces, leading to the formation of volatile organic compounds (VOCs) ${ }^{1-5}$ and secondary organic aerosols, ${ }^{6}$ or acting as sinks for reactive species, such as $\mathrm{NO}_{2}$ or ozone. ${ }^{7-10}$ This interfacial photochemistry is exclusively due to the presence of surfactants which tend to concentrate in surface layers with respect to the underlying bulk water. Additionally, such surfactants also increase the propensity of less surface-active compounds to enrich there as well, creating a unique chemical environment, affecting not only chemistry but also trace-gas exchange. ${ }^{5,10-}$ 16

A major source of biogenic surfactants in the ambient environment are so-called biofilms, loosely defined as a population of microorganisms (i.e., fungi, algae, archaea) that accumulate at an interface. In addition, such microorganisms can also form cellular aggregates not attached to a surface, sometimes also referred to as flocs or sludge, which have very similar characteristics as biofilms. ${ }^{17,18}$ Such polymicrobial communities are ubiquitously found in natural water systems, such as rivers, lakes, and the ocean, ${ }^{12}$ but even in extreme surroundings, such as hydrothermal hot springs, ${ }^{19}$ deep-sea vents, ${ }^{20}$ or space stations. ${ }^{21}$ Typically, biofilms are embedded in an extrapolymeric substance (EPS) matrix, comprising polysaccharides, proteins, nucleic acids, lipids and humic acids, which is encasing and immobilizing the microbial aggregates. ${ }^{18,22}$ While the capsular fraction of the EPS matrix is closely and firmly attached to cell surfaces, the less compact, amorphous slime in the more distant extracellular environment is named the colloidal fraction. Due to the diversity, complexity and heterogeneity, an exact chemical and physical characterization of biofilms still represents a challenging task. ${ }^{18,22}$ Nonetheless, the global presence of surfactants at air/water interfaces of aquatic systems is nowadays attributed to microbiological activity. These biogenic surfactants form surface microlayers (SMLs) and influence biogeochemical and climate-related processes. ${ }^{13,23}$ Furthermore, several studies demonstrated the incorporation of such biogenic surfactants into aerosol particles by primary processes, such as bubble bursting and sea spray formation, increasing the surfactant-covered surface area in the atmosphere by orders of magnitude. ${ }^{24-31}$

Although previous studies demonstrated photo-induced VOC production from surfactants on aqueous solutions, these experiments were typically conducted far from ambient conditions or for a very limited number of samples. ${ }^{1-5}$ However, since biogenic surfactants are omnipresent in the environment, such photochemical processes possibly contribute to a significant extent to ambient VOC concentrations. To investigate this potentially underestimated VOC source under more realistic conditions, in this study, biogenic surfactants were produced from authentic riverine biofilms. Experiments were 
conducted in a photochemical reactor and an atmospheric simulation chamber, to study VOC formation upon irradiation and implications for aerosol formation and growth respectively. The produced VOCs were identified by online atmospheric-pressure chemical ionization high-resolution mass spectrometry (online-APCl-HRMS). VOC emission fluxes were then measured and quantified by proton transfer reaction time-of-flight mass spectrometry (PTR-ToF-MS). In addition, to identify underlying processes and to exclude VOC production from biological processes, the VOC release from biofilm samples of different ages was compared to dead samples. Moreover, freeze-dried biofilm samples were fractionated into cellular, capsular, and colloidal fraction to further investigate which of the compartments is the main driver for surfactant release and, thus, abiotic photochemical VOC production.

\section{Experimental}

\subsection{Biofilm preparation and biological parameters}

Biofilms were grown on glass substrates in aquaria containing $18 \mathrm{~L}$ of groundwater supplemented with $\mathrm{K}_{2} \mathrm{HPO}_{4}\left(345 \mu \mathrm{g} \mathrm{L}{ }^{-1}\right), \mathrm{Na}_{2} \mathrm{SiO}_{3} \cdot 5 \mathrm{H}_{2} \mathrm{O}\left(11.4 \mathrm{mg} \mathrm{L}^{-1}\right)$ and $\mathrm{NaNO}_{3}\left(5.1 \mathrm{mg} \mathrm{L}^{-1}\right)$. The aquaria were incubated at $15^{\circ} \mathrm{C}$, under a $16 / 8 \mathrm{~h}$ day/night cycle. Constant agitation was ensured by an aquarium pump and water was renewed every week. Biofilm inoculum was obtained by scraping natural biofilms on cobbles from a freshwater river (River Morcille, France) or a lake (Lake Annecy, France) and was added once at the beginning of biofilm colonization. Biofilm were dried during $24 \mathrm{~h}$ at $80^{\circ} \mathrm{C}$ to obtain the dry biomass and were thereafter burned at $500^{\circ} \mathrm{C}$ during $1 \mathrm{~h}$ to calculate the ash-free dry weight and the organic matter content. An overview of sampling locations and original biofilm concentrations is given in the electronic supplementary information (Table S-1).

After colonization, biofilm were scraped from glass substrata with a razor blade and gently homogenized in groundwater to obtain a suspension of living biofilm. Living biofilm suspensions were autoclaved $\left(20 \mathrm{~min}\right.$ at $121^{\circ} \mathrm{C}$ ) to obtain suspensions of dead biofilm. Separation of the different biofilm fractions was performed following Aguilera et al. ${ }^{32}$ Briefly, biofilm suspensions were freeze-dried, then $5 \mathrm{ml}$ of deionized water were added to $1.5 \mathrm{~g}$ of freeze-dried sample. Samples were agitated for $20 \mathrm{~min}$ at room temperature before centrifugation $\left(4000 \mathrm{~g}, 15 \mathrm{~min}\right.$ at $20^{\circ} \mathrm{C}$ ). The supernatant was diluted with $20 \mathrm{~mL}$ of deionized water to obtain the colloidal fraction, while $5 \mathrm{~mL}$ of EDTA (Ethylenediaminetetraacetic acid, $10 \mathrm{mM}$ ) were added to the pellet. After 3 hours of agitation at room temperature, diluted pellets were centrifuged $\left(16000 \mathrm{~g}, 20 \mathrm{~min}\right.$ at $\left.20^{\circ} \mathrm{C}\right)$. The supernatant was diluted in $20 \mathrm{~mL}$ of deionized water to obtain the capsular fraction. The residual pellet, diluted in $20 \mathrm{~mL}$ of deionized water contained cellular debris (i.e., cellular fraction). 
VOC production from both living and dead biofilms, as well as from capsular, colloidal and cellular fractions of biofilms were investigated using a photochemical reactor. In addition, experiments using living biofilms were conducted in a multiphase atmospheric simulation chamber.

\subsection{Photochemical reactor}

Biofilm samples of $7 \mathrm{~mL}$ were introduced into a cylindrical glass reactor (length: $86.5 \mathrm{~mm}$, inner diameter: $18.5 \mathrm{~mm})$, thermostated by a water bath $\left(20^{\circ} \mathrm{C}\right)$. A Xenon lamp (150 W; LOTQuantumDesign, France) placed at a distance of $13 \mathrm{~cm}$ from the reactor was used to mimic solar irradiation on the Earth's surface. A quartz water filter of $5 \mathrm{~cm}$ was mounted in front of the lamp to remove infra-red irradiation, whereas short wavelengths $(\lambda<290 \mathrm{~nm})$ were eliminated by a Pyrex filter positioned directly in front of the reactor. A flow of 200-300 mL of zero air (i.e., compressed, filtered and purified air) was pushed continuously through the reactor, and analyzed afterwards either by PTRToF-MS or online-APCI-HRMS. Blank experiments were routinely performed on ground water, which was used for biofilm growth and sample preparation. Typically, after introduction of the biofilm samples and acquisition of a stable background signal, the suspensions were irradiated for 1-3 hours. Experiments were stopped as soon as signals reached background levels again, after switching off the light. A schematic of the experimental setup is given in the supplementary information (Fig. S-1).

\section{$2.3 \quad$ PTR-TOF-MS}

A commercial PTR-ToF-MS (SRI-PTR-ToF-MS 8000, Ionicon Analytik GmbH, Innsbruck, Austria) was used to quantify the emitted VOCs in $\mathrm{H}_{3} \mathrm{O}^{+}$mode. Air was sampled at a constant flow of $100 \mathrm{ml} \cdot \mathrm{min}^{-1}$ at an inlet temperature of $60^{\circ} \mathrm{C}$. Typically, a drift voltage of $600 \mathrm{~V}$, a drift temperature of $60{ }^{\circ} \mathrm{C}$ and a drift pressure of $2.25 \mathrm{mbar}$ were used, resulting in an $E / N$-ratio of about $135 \mathrm{Td}\left(1 \mathrm{Td}=10^{-17} \mathrm{~cm}^{2} \mathrm{~V}^{-1}\right)$. VOC concentrations were calculated according to Cappellin et al. ${ }^{33}$ It should be noted that uncertainties of up to $\pm 30 \%$ may arise for VOC concentrations from systematic errors, since mostly calculated values for the collision rate constants were used. Fluxes for VOCs were calculated according to Ciuraru et al. ${ }^{2}$

\section{4 online-APCI-HRMS}

Identification of VOCs was performed using an Orbitrap high resolution mass spectrometer (Q Exactive, Thermo Scientific, Bremen, Germany) in combination with a modified atmospheric-pressure chemical ionization (APCI) source using corona discharge to produce primary reagent ions. In order to allow the introduction of gaseous species, gas and analyte inlets of the original ion source manifold were changed according to Hoffmann and co-workers. ${ }^{34-36}$ Throughout the experiments the positive mode was used with the following settings: discharge voltage $+5 \mathrm{kV}$, capillary temperature $250^{\circ} \mathrm{C}$, sheath gas 1.0 a.u., auxiliary gas 0.0 a.u., maximum spray current $+5.0 \mu \mathrm{A}$, and probe heater temperature $200^{\circ} \mathrm{C}$. 
Liquid-phase samples were analyzed by reversed phase ultra-high performance liquid chromatography coupled to an Orbitrap high resolution mass spectrometer ( $Q$ Exactive, Thermo Scientific, Bremen, Germany) using heated electrospray ionization (HESI). For the LC separation, a Dionex Ultimate 3000 ultraperformance liquid chromatograph was equipped with a HSS T3 Acquity UPLC column (1.8 $\mu \mathrm{m}$, $2.1 \times 100 \mathrm{~mm}$ ). Acidified water (eluent A; 0.1\%, v/v, formic acid) and acidified acetonitrile (eluent B; $0.1 \%, v / v$, formic acid) were used as mobile phase. An HESI voltage of $-3.0 \mathrm{kV}$ was applied for negative ionization mode measurements. The sheath gas flow rate was set to 42 arbitrary units (a.u.) and the auxiliary gas flow rate to 25 a.u. A capillary temperature of $350^{\circ} \mathrm{C}$ and a heater temperature of $250^{\circ} \mathrm{C}$ were used. All measurement were performed using the highest possible mass resolution $\left(R=1.4 \cdot 10^{7}\right.$ at $\mathrm{m} / \mathrm{z}$ 200). Mass calibration was performed daily for the $\mathrm{m} / \mathrm{z}$ range $<500$ using sodium acetate, as described in Rossignol et al. ${ }^{4}$

Data were processed and evaluated by XCalibur 2.2 (Thermo, USA). Further data analysis was performed using the non-target screening approach of the MZmine 2.21 software package (http://mzmine.github.io). ${ }^{37-39}$ Formula assignments of the identified signals were achieved using a mass tolerance of $2 \mathrm{ppm}$ and the following restrictions for elemental counts: C (1-50), N (0-5), H (0100), O (0-40), S (0-2). Moreover, element count heuristics were applied, ${ }^{38}$ and ring double bond equivalents were restricted to $0-25$. Further details on LC-MS data processing are given in the supplementary information (Table S-3).

\subsection{Surface tension measurements}

All surface tension measurements were performed in triplicate using a Kruss tensiometer K6 (measuring range between 0 and $90 \mathrm{mN} \mathrm{m}^{-1}$ ). Blank experiments were performed before each measurement using purified water (18.2 $\mathrm{M} \Omega)$ and ground water.

\subsection{Multiphase atmospheric simulation chamber}

A detailed description of the chamber experiments can be found elsewhere. ${ }^{6}$ Briefly, particle formation upon oxidation of the produced VOCs was investigated using a $2 \mathrm{~m}^{3}$ chamber made of FEP film (fluorinated ethylene propylene). The chamber was equipped with a glass reservoir at the bottom, which contained the biofilm samples, and surrounded by 12 UV-vis lamps (OSRAM lamps, Eversun L80W/79-R) to mimic solar irradiation. About $30 \mathrm{~mL}$ of a living biofilm suspension (dry biomass $9.7 \mathrm{~g} \mathrm{~L}^{-}$ $\left.{ }^{1}\right)$ were mixed with ca. $30 \mathrm{~L}$ of groundwater in the glass reservoir, eventually giving a rather dilute sample. It should be noted that irradiation of the biofilm sample (67 hours in total) may have stimulated growth of algae and cyanobacteria, changing the original composition of the sample slightly. Particle number concentrations and corresponding size distributions were measured using an ultrafine condensation particle counter (UCPC 3776, TSI, USA) and a scanning mobility particle sizer 
(SMPS 3936, TSI, USA). Ozone was produced by $\mathrm{O}_{2}$ photolysis using a mercury lamp. The resulting $\mathrm{O}_{3}$ concentrations in the chamber were continuously measured (49i, Thermo Scientific, USA).

\section{$3 \quad$ Results and Discussion}

For all investigated biofilm samples an immediate VOC release was observed upon irradiation. Fig. 1 shows an averaged PTR mass spectrum of the analysis of the cellular fraction of a biofilm sample, i.e., only cells without EPS matrix. All signals shown in red were found to increase as soon as the sample was irradiated. Similar observations were also made for all other sample types (i.e., living/dead biofilms, colloidal, and capsular fraction). Thus, the increasing signals possibly correspond to VOCs that are generated due to the presence of biologically-produced and subsequently released compounds, or of degradation products of such compounds from biofilm organisms. It should be noted that VOC production was never observed from irradiation of natural ground water alone, which was used to grow the biofilms in the laboratory. Moreover, all analyzed samples showed similar VOC patterns and relative intensities among the signals were not found to be correlated to original sampling site or biological parameters, such as age or dominating species. Therefore, the detected VOCs are possibly produced due to the presence of compounds which are ubiquitously found in biofilm-containing water systems, such as rivers, lakes, or oceans. ${ }^{17,18,22}$ Furthermore, since VOC release was especially detected for dead samples (i.e., autoclaved biofilms and cellular fraction), direct biological mechanisms can be assumed to have little to no effects on the production of these compounds. Thus, these observations might indicate that VOC production occurred from abiotic photosensitized reactions at the air/water interface of biogenic compounds upon irradiation, as will be further discussed in the following.

Although VOC patterns remained nearly constant for different biofilm samples under different conditions, the detected total flux of VOCs into the gas phase upon irradiation changed significantly among different sample types. Fig. 2, panel (a), shows the total VOC flux (i.e., the sum of fluxes of 69 identified VOCs, see Table S-2), normalized to biofilm dry-weight, for a dead biofilm sample and two living biofilm samples of different ages. In addition, the total VOC flux for ground water is given. For all samples, irradiation was started at time $0 \mathrm{~min}$. As can be seen from this figure, as soon as the light was turned on an immediate increase in VOC fluxes followed for both dead and living biofilms, reaching a constant level after 30-60 minutes. Therefore, it can be assumed that VOCs are not only released from the samples, but are photochemically produced due to irradiation. While the dead biofilm sample gave the highest VOC fluxes, almost no VOC release was observed for ground water alone. Moreover, an increase in VOC fluxes was observed with aging of the biofilms, which were measured five and six days after sampling from the aquarium. Assuming that the number of dead cells is increasing with increasing storage time due to depletion of oxygen and nutrients in the water, this increase in VOC emission fluxes suggests that especially dead or dying cells release the responsible VOC precursor compounds into the bulk water, possibly because of cell lysis after cell death. In agreement with this hypothesis, 
samples containing only the cellular fraction of a biofilm showed the highest VOC fluxes per biofilm dry-weight, as depicted in panel (b) of Fig. 2. In contrast, samples containing only parts of the surrounding EPS, i.e., the capsular and the colloidal fraction, exhibited significantly lower fluxes upon irradiation. It should also be noted that for all samples VOC fluxes decreased immediately after switching off the light, reaching background levels typically after 30-60 minutes, and clearly linking VOC production to irradiation.

Previously, similar observations have already been made for marine SML samples and surfactantcontaining aqueous solutions, which were accounted to photosensitized reactions at the air/water interface. $^{2-5,40}$ In agreement, the same VOC classes were observed for the biofilm samples investigated in this work (Table 1 and Supplementary Information). In particular, not only saturated oxygenated VOCs, such as aldehydes and ketones, but also unsaturated and functionalized VOCs were observed (e.g., alkenes, dienes, unsaturated aldehydes or ketones). Since the formation of such mono- and polyunsaturated compounds is, however, not favored in the bulk water, ${ }^{41}$ the production of these compounds probably occurs in an organic-enriched environment, as it can typically be found at the air/water interface of surfactant-containing aqueous solutions. Thus, especially less water-soluble substances, released into the bulk water from biofilm cells, might form a microlayer at the surface of the biofilm samples and drive the observed photo-induced VOC production. As can be seen from Table 1, calculated VOC fluxes of a living biofilm sample for ambient conditions (i.e., mean solar flux of $9.2 \mathrm{~mW} \mathrm{~cm}^{-2}$ ) were typically in the range of $10^{7}$ molecules $\mathrm{cm}^{-2} \mathrm{~s}^{-1}$. However, VOC fluxes for dead biofilm samples often reached emission rates of $10^{8}$ molecules $\mathrm{cm}^{-2} \mathrm{~s}^{-1}$ (Table S-2). Previously, VOC fluxes in the same range have been measured during field studies in the marine environment and during laboratory experiments. ${ }^{3,42}$

It has been demonstrated that photosensitizers, e.g., humic acids, can initiate photochemical VOC production in the presence of surfactants by transition to a triplet state after UV/Vis-absorption. 2,3,5,10,40 Subsequently, such excited molecules can trigger radical chemistry through $\mathrm{H}$-abstraction from other organics, such as fatty acids, followed by addition of molecular oxygen. ${ }^{43,44}$ Furthermore, photosensitizers were shown to be enriched in SMLs on aqueous solutions, ${ }^{5,45,46}$ thus, probably enhancing such photochemical processes there. In addition, Rossignol et al. recently showed that photo-induced radical-chemistry occurs even in the absence of a classical photosensitizer from a pure fatty acid microlayer. ${ }^{4}$ Therefore, it seems likely that similar photosensitized processes at the air/water interface explain the observed VOC production from biofilm-containing solutions in this study. Furthermore, due to the ubiquity of microorganisms and biofilms in the ambient environment, it has to be assumed that similar processes occur globally on a large scale at air/water interfaces, e.g., of oceans, lakes, rivers, but even aerosol particles and cloud droplets. 
Supporting the hypothesis of photosensitized VOC production, the liquid phase analysis of the biofilm samples by LC-HRMS indicated the presence of surfactants, such as fatty acids, as well as known photosensitizers, e.g., oxo-fatty acids (Table S-4). A wide range of these compounds has known biological sources, since they serve a variety of purposes, e.g., in cell walls, membranes, and protein modifications, but also as energy storage, such as triacylglycerides, as building blocks for primary and secondary metabolites, or even as messenger molecules. ${ }^{18,47}$ Previous studies have shown that lipids, such as phospholipids, glycolipids, and triacylglycerides, are released after cell lysis of phytoplankton cells into the bulk water. Subsequent enzymatic digestion then leads to formation of saturated and unsaturated fatty acids. ${ }^{29,48,49}$ In addition, longer-chain fatty acids can further decompose to short chain fatty acid derivatives. ${ }^{50,51}$ Moreover, fatty acids are also known components of the EPS matrix surrounding the cells in biofilms. ${ }^{18,52,53}$

In contrast to the other fatty acid classes, oxo-fatty acids have been observed previously to be produced also by photo-oxidation, ${ }^{51}$ besides enzymatic digestion. ${ }^{54}$ Moreover, similar oxidation products have been found earlier from irradiation of a microlayer of a saturated fatty acid and were attributed to photo-induced peroxy-radical chemistry. ${ }^{2-5}$ In agreement with these observations, the abundance of oxo-fatty acids increased after irradiation of the biofilm samples. In addition to the oxofatty acids, abundances of other acidic compounds increased upon irradiation. Table 2 gives an overview of compound classes that exhibited an elevated abundance after irradiation of the cellular fraction. It should be noted that all compounds increasing for the cellular fraction also increased for both the capsular and colloidal fraction, even though signal intensities were typically lower for these sample types. As can be seen from the table, besides carboxylic acids, the abundance of carbonylcontaining compounds (i.e., aldehydes/ketones) increased as well, further supporting the assumption of photosensitized degradation of fatty acids. Moreover, the formation of dicarboxylic acids can possibly be explained to a certain extent by the formation of dimerization products after radical formation, although it was shown to be less favored in the presence of oxygen. ${ }^{4,5}$ Due to the broad range of products observed, the discrimination of exact reaction mechanisms seems, however, not possible here. Nonetheless, the results indicate that irradiation induces a rich, abiotic chemistry at the air/water interface of biofilm-containing samples.

In general, the $\mathrm{O} / \mathrm{C}$ ratios for the majority of detected compounds in the liquid phase was found to be less than 1, suggesting the presence of more aliphatic-like substances. It should, however, be noted that the LC-MS results are biased towards surface-active compounds with low enthalpies of deprotonation, since ionization of such compounds is favored by the ESI process. Therefore, compounds with higher $\mathrm{O} / \mathrm{C}$ ratios, such as saccharides, probably gave little to no signal intensity in the acquired mass spectra despite high concentrations in the EPS matrix as they are known to exhibit 
a poor ionization efficiency. ${ }^{17,18,29,55}$ Therefore, changes in the abundance of such compounds due to photochemistry cannot be discussed here.

In agreement with the assumption that cell lysis is a main source for biogenic surfactants at the air/water interface, the surface tension of untreated biofilm samples decreased with increasing storage time and, thus, with an increase of dead cells in the sample. As depicted in Fig. 3, a relatively high surface tension of $71.7 \mathrm{mN} \mathrm{m}^{-1}$ was measured directly after sampling for a rather lowconcentrated biofilm sample (13.5 $\mathrm{mg} \mathrm{mL}^{-1}$ of biofilm dry-weight). However, already a few hours later a significant decrease in surface tension was observed, eventually giving $69.0 \mathrm{mN} \mathrm{m}^{-1}$ after 100 hours. Interestingly, the same surface tension was reached in less than one hour if the same biofilm sample was sonicated for $3 \mathrm{~min}$ in an ultrasonic bath. Since sonication is a standard procedure to induce cell lysis, ${ }^{56}$ this finding indicates that especially inner-cell components, released into the bulk, become enriched at the air/water interface, decreasing the surface tension of the sample. Further supporting this assumption, the cellular fraction of biofilm samples typically gave the lowest values for surface tension after separation from the capsular and colloidal fraction.

Consistent with these observations, Wurl et al. suggested previously that the SML of oligotrophic regions of the ocean is enriched in surfactants compared to biologically more active regions. It was found that surfactants are globally enriched to a large extent at the air/water interface, especially during fall. ${ }^{13}$ Similarly, O'Dowd et al. demonstrated that during the demise of phytoplankton blooms large quantities of organic matter, comprising exudates, cell debris, and colloidal material, are released into the bulk water due to cell lysis. Subsequently, these compounds accumulate at the ocean's surface and, thus, in primary marine aerosol particles. ${ }^{28}$ In addition, it was shown that the well-established chlorophyll-a concentration as a proxy for biological activity and the enrichment of organic matter in sea spray aerosols do not necessarily correlate. ${ }^{27}$ However, besides implications for sea spray aerosols, the release of biogenic surfactants from cells might have additional effects on atmospheric processes due to photochemical production of VOCs at the air/water interface, as discussed here.

In order to assess the possible impact of the produced VOCs on the atmosphere's oxidation potential, aerosol particle formation, and growth, biofilm samples were injected into a glass reservoir at the bottom of an atmospheric simulation chamber. After irradiation and resulting production of VOCs for several hours, ozone was injected in the dark, reaching a maximum of $600 \mathrm{ppb}$. As can be seen in Fig. 4, new particle formation occurred in the chamber directly afterwards, indicating the formation and nucleation of low-volatile oxidation products. Although the ozone concentration in the chamber was far from ambient levels, it should be noted that only in this way a quick formation of oxidation products and, thus, homogenous nucleation can be reached, whereas at lower ozone concentrations oxidation products would condense on the chamber walls instead of forming particles. Since ozone solely reacts with double bonds, this finding clearly demonstrates the presence of unsaturated VOCs, as already 
suggested from high resolution mass spectra of the online-APCI-HRMS measurements. Interestingly, after an initial growth phase the particle diameters remained rather stable below $20 \mathrm{~nm}$ for roughly $200 \mathrm{~min}$. Although the composition of particles was not further analyzed in this study, the formation of such small and stable aerosol particles possibly points to the formation of very stable and lowvolatile acid-base clusters, or even reaction products, as it was previously shown in laboratory and field studies. ${ }^{57-60}$ Further supporting this assumption, nitrogen-containing compounds, e.g., $\mathrm{C}_{4} \mathrm{H}_{7} \mathrm{~N}$, are among the produced VOCs and can possibly act as bases in such processes (Table 1 and Table S-2).

To study the effect of $\mathrm{OH}$-oxidation, UV lights were turned on after $300 \mathrm{~min}$, accompanied by a second ozone injection. As can be seen from Fig. 4, an immediate particle growth followed, demonstrating the oxidation of yet unreacted VOCs and the formation of further low-volatile compounds, condensing on already existing particles. Surprisingly, a third injection of ozone after another $80 \mathrm{~min}$ led to a weak but clearly visible new particle formation, further suggesting a rapid formation of stable clusters in the lower nm-range from low-volatile oxidation products. Although these rather qualitative results do not allow a parameterization of the particle formation potential of the produced VOCs, it can be assumed that similar processes occur globally in the ambient environment. Considering solely the air/water interface of the ocean, covering $>70 \%$ of the Earth's surface, even small changes in atmospheric chemical processes, such as ozone depletion or aerosol formation, can have tremendous effects on a global scale for cloud formation, radiation budget and, thus, climate change. However, abiotic photoinduced VOC production and resulting implications are up to now not captured by atmospheric chemistry or climate models. ${ }^{25,61,62}$

\section{Conclusion}

In this work, photochemical processes of surfactants at the air/water interface of biofilm-containing solutions were studied. For the first time, it was shown that surfactants, originating from authentic biological material, can lead to significant abiotic production of unsaturated and functionalized VOCs upon irradiation. In particular, VOC fluxes increased with dying organisms in the samples, suggesting cell lysis to be a main source for biogenic surfactants that serve as VOC precursors. In agreement, strong VOC production was observed upon irradiation of the cellular fraction of biofilm samples, whereas VOC release for matrix components (i.e., colloidal and capsular fraction) remained rather moderate. LC-MS data of liquid phase samples indicated the presence of known surfactant and photosensitizers, such as fatty acids and oxo-fatty acids, supporting the hypothesis of photo-induced peroxy-radical chemistry as source for the observed VOC production. VOC fluxes for living and dead biofilm samples were found to be in the range of previous field observations and laboratory experiments, suggesting that the observed processes may occur to a similar extent in the ambient environment. It should, however, be noted that up to now such VOC emissions were solely accounted to processes directly driven by biology, i.e., high biological activity entails high VOC emissions. In 
contrast, the observed results suggest that especially in oligotrophic and, thus, less biologically-active regions abiotic photochemistry might lead to similar emissions into the atmosphere, as summarized in Fig. 5. Furthermore, it was shown in chamber experiments that the released VOCs can have significant implications for the oxidation potential of the atmosphere and may lead to aerosol formation and growth. Oxidation by dark ozonolysis and subsequent particle formation clearly proved the formation and release of unsaturated VOCs. Since biogenic surfactants can be regarded as ubiquitous at air/water interfaces, e.g., on rivers, lakes, ocean, aerosol particles, and cloud droplets, it has to be assumed that photo-induced abiotic VOC production occurs globally, influencing atmospheric chemical and climatic mechanisms, such as ozone chemistry or aerosol and cloud formation, on a large scale.

\section{Acknowledgements}

This study was supported by the European Research Council under the European Union's Framework Program (FP/2007-2013) / ERC Grant Agreement 290852 - AIRSEA. This project has also received funding from the European Union's Horizon 2020 research and innovation programme under grant agreement No. 730997 (EUROCHAMP2020). This project has received funding from the European Union's Horizon 2020 research and innovation programme under grant agreement No 690958. The authors are grateful to Antoinette Boréave and Nicolas Charbonnel for the technical support provided by the Institut de Recherches sur la Catalyse et l'Environnement de Lyon (IRCELYON). 


\section{References}

1 H. Fu, R. Ciuraru, Y. Dupart, M. Passananti, L. Tinel, S. Rossignol, S. Perrier, D. J. Donaldson, J. Chen and C. George, J. Am. Chem. Soc., 2015, 137, 8348-8351.

2

5 R. Ciuraru, L. Fine, M. van Pinxteren, B. D’Anna, H. Herrmann and C. George, Environ. Sci. Technol., 2015, 49, 13199-13205.

R. Ciuraru, L. Fine, M. van Pinxteren, B. D'Anna, H. Herrmann and C. George, Sci. Rep., 2015, 5, 12741.

S. Rossignol, L. Tinel, A. Bianco, M. Passananti, M. Brigante, D. J. Donaldson and C. George, Science, 2016, 353, 699-702.

L. Tinel, S. Rossignol, A. Bianco, M. Passananti, S. Perrier, X. Wang, M. Brigante, D. J. Donaldson and C. George, Environ. Sci. Technol., 2016, 50, 11041-11048.

F. Bernard, R. Ciuraru, A. Boréave and C. George, Environ. Sci. Technol., 2016, 50, 8678-8686. A. Jammoul, S. Dumas, B. D'Anna and C. George, Atmos. Chem. Phys., 2009, 9, 4229-4237. D. I. Reeser, A. Jammoul, D. Clifford, M. Brigante, B. D’Anna, C. George and D. J. Donaldson, J. Phys. Chem. C, 2009, 113, 2071-2077.

C. George, M. Ammann, B. D'Anna, D. J. Donaldson and S. A. Nizkorodov, Chem. Rev., 2015, $115,4218-4258$.

L. J. Carpenter and P. D. Nightingale, Chem. Rev., 2015, 115, 4015-4034.

D. J. Donaldson and V. Vaida, Chem. Rev., 2006, 106, 1445-61.

M. Cunliffe, R. C. Upstill-Goddard and J. C. Murrell, FEMS Microbiol. Rev., 2011, 35, 233-246.

O. Wurl, E. Wurl, L. Miller, K. Johnson and S. Vagle, Biogeosciences, 2011, 8, 121-135.

O. Wurl, C. Stolle, C. Van Thuoc, P. The Thu and X. Mari, Prog. Oceanogr., 2016, 144, 15-24.

R. J. Rapf and V. Vaida, Phys. Chem. Chem. Phys., 2016, 18, 20067-20084.

R. J. Perkins, A. Kukharchuk, P. Delcroix, R. K. Shoemaker, M. Roeselová, L. Cwiklik and V. Vaida, J. Phys. Chem. B, 2016, 120, 7408-7422.

L. Hall-Stoodley, J. W. Costerton and P. Stoodley, Nat. Rev. Microbiol., 2004, 2, 95-108.

H.-C. Flemming and J. Wingender, Nat. Rev. Microbiol., 2010, 8, 623-33.

A. L. Reysenbach and S. L. Cady, Microbiology of ancient and modern hydrothermal systems, Elsevier, 2001, vol. 9.

C. D. Taylor, C. O. Wirsen and F. Gaill, Appl Env. Microbiol, 1999, 65, 2253-2255.

C. M. Ott, R. J. Bruce and D. L. Pierson, Microb. Ecol., 2004, 47, 133-136.

H.-C. Flemming, T. R. Neu and D. J. Wozniak, J. Bacteriol., 2007, 189, 7945-7.

M. Cunliffe, Appl. Environ. Microbiol., 2013, 79, 738-40.

R.-S. Tseng, J. T. Viechnicki, R. A. Skop and J. W. Brown, J. Geophys. Res., 1992, 97, 5201.

D. J. Donaldson and C. George, Environ. Sci. Technol., 2012, 46, 10385-10389.

N. Meskhidze, M. D. Petters, K. Tsigaridis, T. Bates, C. O'Dowd, J. Reid, E. R. Lewis, B. Gantt, M.

D. Anguelova, P. V. Bhave, J. Bird, A. H. Callaghan, D. Ceburnis, R. Chang, A. Clarke, G. de Leeuw, G. Deane, P. J. DeMott, S. Elliot, M. C. Facchini, C. W. Fairall, L. Hawkins, Y. Hu, J. G. Hudson, M. S. Johnson, K. C. Kaku, W. C. Keene, D. J. Kieber, M. S. Long, M. Mårtensson, R. L. Modini, C. L. Osburn, K. A. Prather, A. Pszenny, M. Rinaldi, L. M. Russell, M. Salter, A. M. Sayer, A. Smirnov, S. R. Suda, T. D. Toth, D. R. Worsnop, A. Wozniak and S. R. Zorn, Atmos. Sci. Lett., 2013, 14, 207-213.

P. K. Quinn, T. S. Bates, K. S. Schulz, D. J. Coffman, A. A. Frossard, L. M. Russell, W. C. Keene

and D. J. Kieber, Nat. Geosci., 2014, 7, 228-232.

Connan, M. Rinaldi, S. Fuzzi, S. Decesari, M. Cristina Facchini, S. Marullo, R. Santoleri, A. Dell'Anno, C. Corinaldesi, M. Tangherlini and R. Danovaro, Sci. Rep., 2015, 5, 14883.

29 R. E. Cochran, O. Laskina, T. Jayarathne, A. Laskin, J. Laskin, P. Lin, C. Sultana, C. Lee, K. A. Moore, C. D. Cappa, T. H. Bertram, K. A. Prather, V. H. Grassian and E. A. Stone, Environ. Sci. Technol., 2016, 50, 2477-2486.

30 R. E. Cochran, T. Jayarathne, E. A. Stone and V. H. Grassian, J. Phys. Chem. Lett., 2016, 7, 1692-1696.

31 T. Jayarathne, C. M. Sultana, C. Lee, F. Malfatti, J. L. Cox, M. A. Pendergraft, K. A. Moore, F. 
Azam, A. V. Tivanski, C. D. Cappa, T. H. Bertram, V. H. Grassian, K. A. Prather and E. A. Stone, Environ. Sci. Technol., 2016, 50, 11511-11520.

A. Aguilera, V. Souza-Egipsy, P. San Martín-Úriz and R. Amils, Appl. Microbiol. Biotechnol., 2008, 78, 1079-1088.

L. Cappellin, T. Karl, M. Probst, O. Ismailova, P. M. Winkler, C. Soukoulis, E. Aprea, T. D. Märk,

F. Gasperi and F. Biasioli, Environ. Sci. Technol., 2012, 46, 2283-90.

Ulrich Kückelmann, and Bettina Warscheid and T. Hoffmann, 2000.

B. Warscheid and T. Hoffmann, Atmos. Environ., 2001, 35, 2927-2940.

T. Hoffmann, R. Bandur, S. Hoffmann and B. Warscheid, Spectrochim. Acta Part B At. Spectrosc., 2002, 57, 1635-1647.

37 T. Pluskal, S. Castillo, A. Villar-Briones and M. Oresic, BMC Bioinformatics, 2010, 11, 395.

38 T. Pluskal, T. Uehara and M. Yanagida, Anal. Chem., 2012, 84, 4396-4403. M. Hu, M. Krauss, W. Brack and T. Schulze, Anal. Bioanal. Chem., 2016, 408, 7905-7915. R. Chiu, L. Tinel, L. Gonzalez, R. Ciuraru, F. Bernard, C. George and R. Volkamer, Geophys. Res. Lett., 2016, 33.

41 J. B. Gilman, T. L. Eliason, A. Fast and V. Vaida, J. Colloid Interface Sci., 2004, 280, 234-243.

S. L. Shaw, B. Gantt and N. Meskhidze, Adv. Meteorol., 2010, 2010, 1-24.

C. S. Foote, Science, 1968, 162.

C. S. Foote, Photochem. Photobiol., 1991, 54, 659-659.

D. J. Carlson and L. M. Mayer, Nature, 1980, 286, 482-483.

D. J. Carlson, Limnol. Oceanogr., 1983, 28, 415-431.

J. Beld, D. J. Lee and M. D. Burkart, Mol. BioSyst., 2015, 11, 38-59.

S. M. Budge, E. Devred, M.-H. Forget, V. Stuart, M. K. Trzcinski, S. Sathyendranath and T. Platt, ICES J. Mar. Sci., 2014, 71, 1885-1893.

K. Hayakawa, N. Handa, K. Kawanobe and C. S. Wong, Mar. Chem., 1996, 52, 233-244.

50 R. Gupta, N. Gupta and P. Rathi, Appl. Microbiol. Biotechnol., 2004, 64, 763-781.

51 J. F. Rontani, B. Charriere, M. Petit, F. Vaultier, H. J. Heipieper, H. Link, G. Chaillou and R. Sempéré, Biogeosciences, 2012, 9, 3513-3530.

52 A. Conrad, M. Kontro, M. M. Keinänen, A. Cadoret, P. Faure, L. Mansuy-Huault and J.-C. Block, Lipids, 2003, 38, 1093-1105.

53 M. Marvasi, P. T. Visscher and L. Casillas Martinez, FEMS Microbiol. Lett., 2010, 313, 1-9.

54 A. Suresh Kumar, K. Mody and B. Jha, J. Basic Microbiol., 2007, 47, 103-117.

55 F. N. Lamari, R. Kuhn and N. K. Karamanos, J. Chromatogr. B, 2003, 793, 15-36.

56 P. Zhang, G. Zhang and W. Wang, Ultrasonic treatment of biological sludge: Floc disintegration, cell lysis and inactivation, 2007, vol. 98.

57 X. Tang, D. Price, E. Praske, S. A. Lee, M. A. Shattuck, K. Purvis-Roberts, P. J. Silva, A. AsaAwuku and D. R. Cocker, Atmos. Environ., 2013, 72, 105-112.

58 C. Qiu and R. Zhang, Phys. Chem. Chem. Phys., 2013, 15, 5738.

59 M. M. Galloway, M. H. Powelson, N. Sedehi, S. E. Wood, K. D. Millage, J. A. Kononenko, A. D. Rynaski and D. O. De Haan, Environ. Sci. Technol., 2014, 48, 14417-14425.

60 G. Duporté, J. Parshintsev, L. M. F. Barreira, K. M. Hartonen, M. Kulmala and M.-L. Riekkola, Environ. Sci. Technol., 2016, 50, 4693-4700.

61 P. S. Liss and A. R. Duce, The Sea Surface and Global Change, Cambridge University Press, 2005.

M. G. Ehrhardt and R. R. Weber, Fresenius. J. Anal. Chem., 1995, 352, 357-363. 


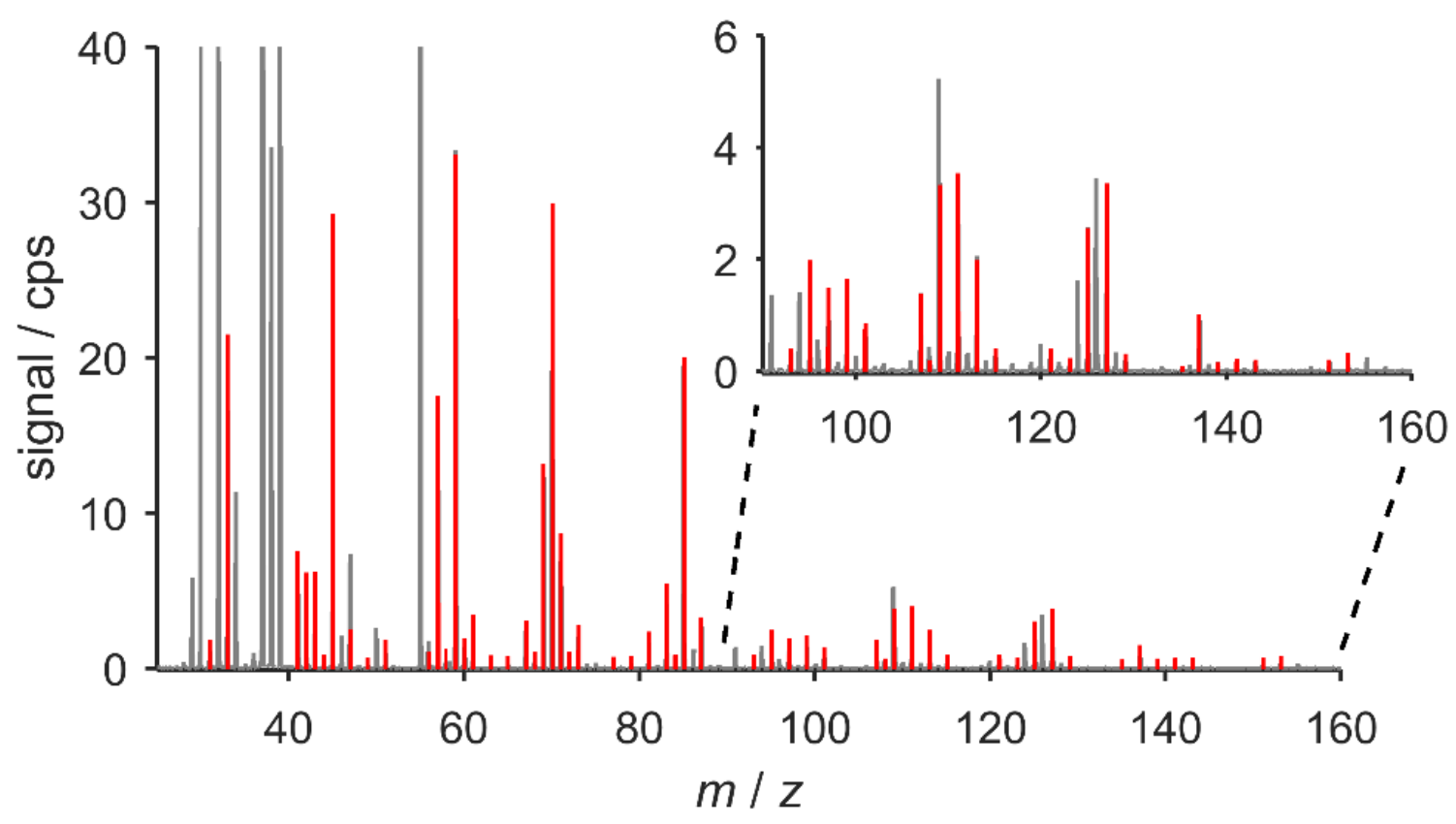

Fig. 1 Average PTR mass spectrum during irradiation of the cellular fraction of biofilms. Signals in red increased for all biofilm sample types. Background signals are depicted in gray and typically correspond to primary ions or protonated water clusters (for a better visibility the $y$-axis is allowed to go off scale for such signals). The inset shows a zoom-in of the spectrum in the $\mathrm{m} / \mathrm{z}$ range $90-160$. 
a)

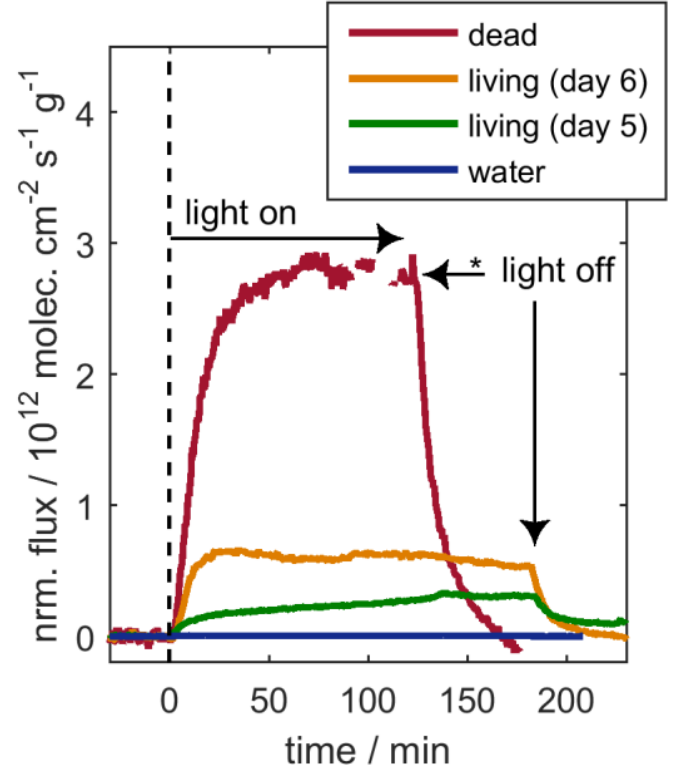

b)

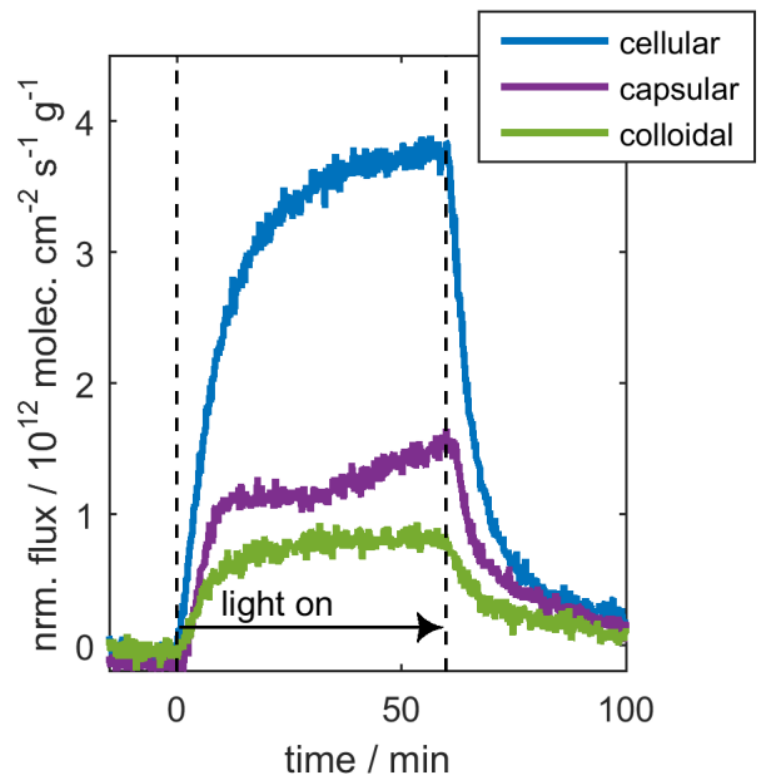

Fig. 2 Observed fluxes from PTR-MS measurements (normalized to biofilm dry-weight) upon sample irradiation for the sum of increasing signals (Table S-2) as a function of time: (a) Fluxes for autoclaved (i.e., dead) and authentic (i.e., living) biofilms for two different days. In addition, observed fluxes of a ground water experiment are given as background. (*Irradiation of the dead biofilm sample was stopped after $120 \mathrm{~min}$, while the other samples were irradiated for $180 \mathrm{~min}$.) (b) Normalized fluxes for the cellular, capsular, and colloidal fraction of a biofilm sample upon irradiation. 


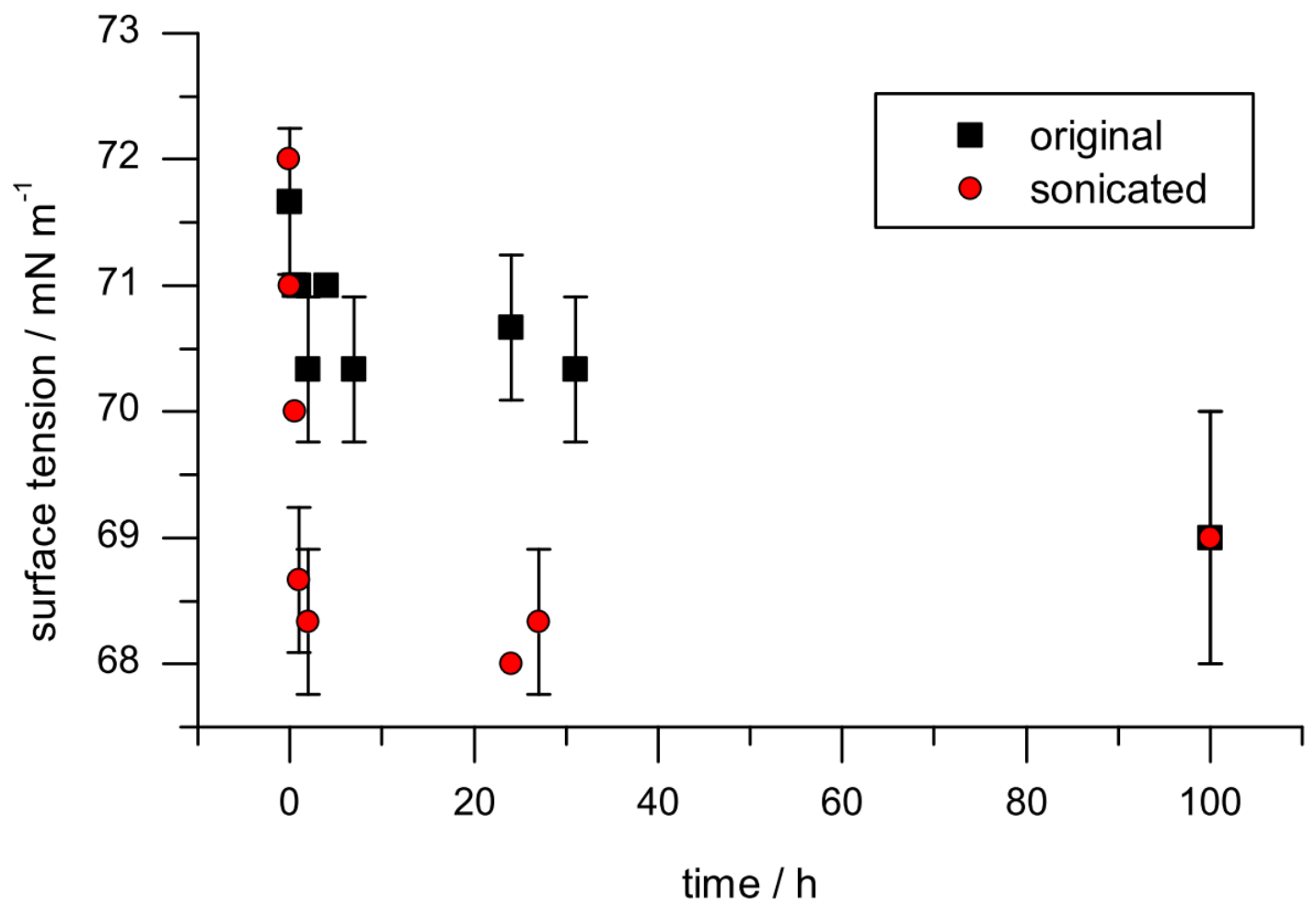

Fig. 3 Surface tension of an untreated (black squares) and a sonicated (red dots) biofilm sample as a function of time; error bars indicate one standard deviation of three measurements. 


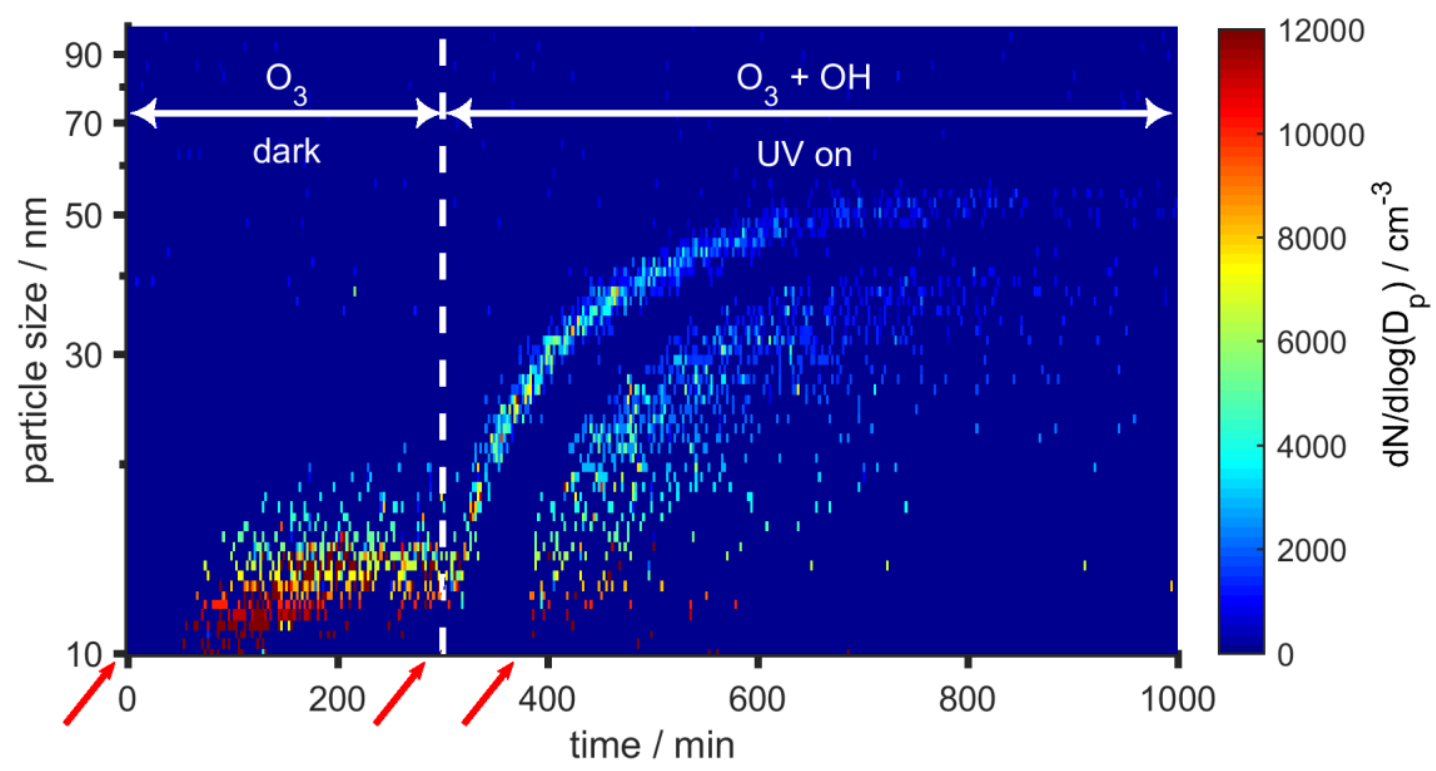

Fig. 4 Number particle size distribution after ozone injection as a function of time for a chamber experiment. Red arrows indicate ozone injections (reaching ca. $600 \mathrm{ppb}$ ). Biofilms were irradiated prior to ozone injection for 67 hours to induce VOC production. After 300 min of dark ozonolysis, the UV lights were turned on together with a second ozone injection to initiate $\mathrm{OH}$ radical chemistry. At minute 380, ozone was injected a third time. 


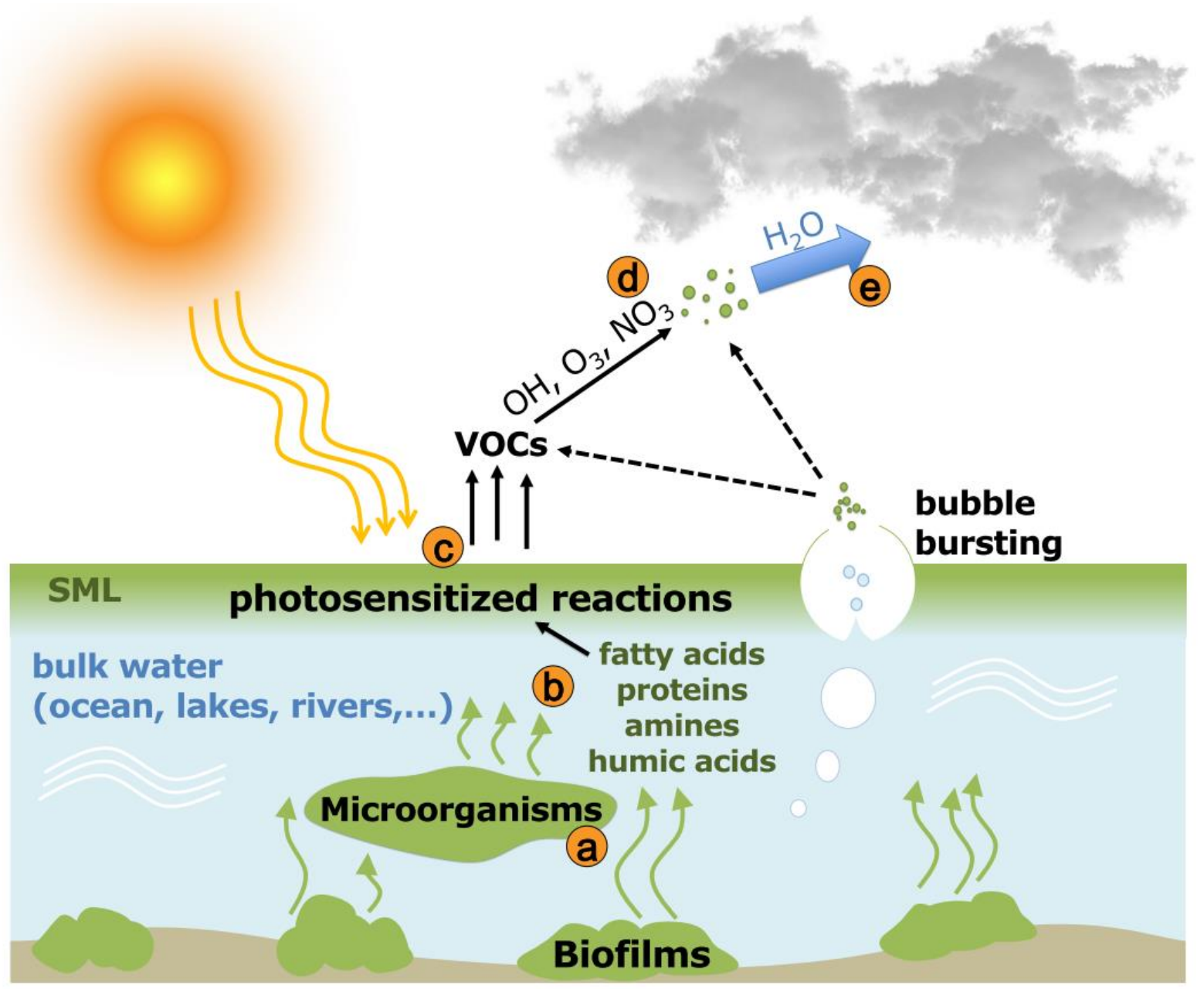

Fig. 5 Interfacial photochemistry of biogenic surfactants as a major source of VOCs. (a) Cell lysis of dying biofilm organisms results in release of cytoplasm and other cell components into the bulk water. (b) Less watersoluble compounds, such as fatty acids, are enriched in the SML at the air/water interface where (c) photosensitized reactions are induced by sunlight. The resulting VOCs partition into the gas phase. (d) Atmospheric oxidation, e.g., by ozone or $\mathrm{OH}$ radicals, leads to organic aerosol formation which (e) eventually influences cloud formation and lifetime. Bubble bursting might even enhance the above explained mechanisms due to an increase in aerosol surface area and, thus, a larger surfactant-enriched air/water interface. 
Table 1 Some of the identified VOCs, corresponding production rates, and calculated fluxes under ambient conditions for the living biofilm samples (day 6). A complete list of all detected VOCs is given in the electronic supplementary information (Table S-2). Production rates are calculated for a total lamp output of ca. $26 \mathrm{~mW} \mathrm{~cm}^{-}$ 2 in the wavelength range of 280-420 nm. Ambient VOC fluxes are calculated for a mean solar flux of $9.2 \mathrm{~mW}$ $5 \mathrm{~cm}^{-2}$ in the same wavelength range at a solar zenith angle of $0^{\circ}$.

\begin{tabular}{|c|c|c|c|c|}
\hline \multicolumn{2}{|c|}{ measured $m / z\left([\mathrm{M}+\mathrm{H}]^{+}\right)$} & \multirow{2}{*}{$\begin{array}{l}\text { assigned } \\
\text { formula }\end{array}$} & \multirow{2}{*}{$\begin{array}{c}\text { production / } \\
10^{7} \text { molec. } \mathrm{mW}^{-1} \mathrm{~s}^{-1}\end{array}$} & \multirow{2}{*}{$\begin{array}{l}\text { flux (ambient) / } \\
10^{7} \text { molec. } \mathrm{cm}^{-2} \mathrm{~s}^{-1}\end{array}$} \\
\hline APCI-HRMS & PTR-ToF-MS & & & \\
\hline 51.0611 & 51.043 & $\mathrm{CH}_{6} \mathrm{O}_{2}$ & 1.90 & 17.4 \\
\hline 57.0336 & 57.032 & $\mathrm{C}_{3} \mathrm{H}_{4} \mathrm{O}$ & 5.36 & 49.1 \\
\hline 57.0700 & 57.067 & $\mathrm{C}_{4} \mathrm{H}_{8}$ & 4.06 & 37.2 \\
\hline 59.0492 & 59.047 & $\mathrm{C}_{3} \mathrm{H}_{6} \mathrm{O}$ (acetone) & 77.4 & 710 \\
\hline 69.0698 & 69.067 & $\mathrm{C}_{5} \mathrm{H}_{8}$ (isoprene) & 4.79 & 43.9 \\
\hline 70.0651 & 70.061 & $\mathrm{C}_{4} \mathrm{H}_{7} \mathrm{~N}$ & 1.70 & 15.6 \\
\hline 71.0491 & 71.045 & $\mathrm{C}_{4} \mathrm{H}_{6} \mathrm{O}$ & 2.40 & 22.0 \\
\hline 73.0284 & 73.061 & $\mathrm{C}_{3} \mathrm{H}_{4} \mathrm{O}_{2}$ & 0.125 & 1.15 \\
\hline 83.0855 & 83.080 & $\mathrm{C}_{6} \mathrm{H}_{10}$ & 2.32 & 21.3 \\
\hline 85.0647 & 85.059 & $\mathrm{C}_{5} \mathrm{H}_{8} \mathrm{O}$ & 1.58 & 14.4 \\
\hline 127.1116 & 127.101 & $\mathrm{C}_{8} \mathrm{H}_{14} \mathrm{O}$ & 1.18 & 10.8 \\
\hline 153.1273 & 153.114 & $\mathrm{C}_{10} \mathrm{H}_{16} \mathrm{O}$ & 0.281 & 2.57 \\
\hline
\end{tabular}


Table 2 Compounds and compound classes that were increasing after irradiation of the cellular fraction, identified by (-)-ESI-UHPLC-HRMS. In general, signals increasing for the cellular fraction also increased for the capsular and colloidal fraction.

\begin{tabular}{|c|c|c|}
\hline Assigned compound class & General formula & Carbon range $(n=\ldots)$ \\
\hline saturated fatty acids & $\mathrm{C}_{\mathrm{n}} \mathrm{H}_{2 \mathrm{n}} \mathrm{O}_{2}$ & 3,5 \\
\hline Unsaturated fatty acids & $\begin{array}{l}\mathrm{C}_{\mathrm{n}} \mathrm{H}_{2 \mathrm{n}-2} \mathrm{O}_{2} \\
\mathrm{C}_{\mathrm{n}} \mathrm{H}_{2 \mathrm{n}-4} \mathrm{O}_{2} \\
\mathrm{C}_{n} \mathrm{H}_{2 \mathrm{n}-6} \mathrm{O}_{2}\end{array}$ & $6-12$ \\
\hline Saturated Oxo-Fatty acids & $\mathrm{C}_{\mathrm{n}} \mathrm{H}_{2 \mathrm{n}-2} \mathrm{O}_{3}$ & $5-16$ \\
\hline Unsaturated Oxo-Fatty acids & $\mathrm{C}_{\mathrm{n}} \mathrm{H}_{2 \mathrm{n}-4} \mathrm{O}_{3}$ & $12-18$ \\
\hline Hydroxy-Fatty acids & $\mathrm{C}_{\mathrm{n}} \mathrm{H}_{2 \mathrm{n}} \mathrm{O}_{3}$ & $5-12$ \\
\hline Saturated Dicarboxylic acids & $\mathrm{C}_{\mathrm{n}} \mathrm{H}_{2 \mathrm{n}-2} \mathrm{O}_{4}$ & $8-18$ \\
\hline Unsaturated Dicarboxylic acids & $\mathrm{C}_{\mathrm{n}} \mathrm{H}_{2 \mathrm{n}-4} \mathrm{O}_{4}$ & $7-18$ \\
\hline $\begin{array}{l}\text { Saturated Ketones/aldehydes } \\
\text { (unsaturated alcohols) }\end{array}$ & $\mathrm{C}_{n} \mathrm{H}_{2 \mathrm{n}} \mathrm{O}$ & 5 \\
\hline Unsaturated Ketones/aldehydes & $\mathrm{C}_{n} \mathrm{H}_{2 n-2} \mathrm{O}$ & $4-7$ \\
\hline
\end{tabular}

